\title{
Hombres y rejas. El APRA en prisión, 1932-1945
}

Hommes et barreaux. L'APRA en prison, 1932-1945

Men and prison bars: APRA in the penitentiary, 1932-1945

\section{Carlos Aguirre}

\section{OpenEdition}

\section{Journals}

Edición electrónica

URL: http://journals.openedition.org/bifea/4234

DOI: $10.4000 /$ bifea.4234

ISSN: 2076-5827

\section{Editor}

Institut Français d'Études Andines

\section{Edición impresa}

Fecha de publicación: 1 mayo 2014

Paginación: 7-30

ISSN: 0303-7495

\section{Referencia electrónica}

Carlos Aguirre, «Hombres y rejas. El APRA en prisión, 1932-1945 », Bulletin de l'Institut français d'études andines [En línea], 43 (1) | 2014, Publicado el 08 mayo 2014, consultado el 05 noviembre 2020. URL : http://journals.openedition.org/bifea/4234 ; DOI : https://doi.org/10.4000/bifea.4234

Les contenus du Bulletin de l'Institut français d'études andines sont mis à disposition selon les termes de la licence Creative Commons Attribution - Pas d'Utilisation Commerciale - Pas de Modification 4.0 International. 


\title{
Hombres y rejas. El APRA en prisión, 1932-1945*
}

\author{
Carlos Aguirre**
}

\begin{abstract}
Resumen
Este artículo analiza diversos aspectos de la prisión política de dirigentes y militantes apristas entre 1932 y 1945 y busca introducir matices en la versión oficial partidaria que suele enfatizar el heroísmo y sacrificio de quienes padecieron encierro y maltrato por parte de regímenes autoritarios. El artículo pasa revista a las formas de organización, comunicación y resistencia de los presos políticos, sus relaciones con los presos comunes, las ventajas o privilegios de los que a veces disfrutaban algunos de los detenidos y el uso de redes de amistad para aminorar los efectos de la represión. La conclusión enfatiza la importancia de analizar la prisión política como un elemento central en la evolución del partido aprista.
\end{abstract}

Palabras clave: APRA, prisión política, tortura, resistencia, represión, presos comunes

\section{Hommes et barreaux. L'APRA en prison, 1932-1945}

\section{Résumé}

Cet article analyse divers aspects de la prison politique chez des dirigeants et militants apristes entre 1932 et 1945, et cherche à nuancer la version officielle partisane qui tend à mettre I'accent sur l'héroïsme et le sacrifice de ceux qui ont souffert l'enfermement et les mauvais traitements sous les régimes autoritaires. L'article passe en revue les formes d'organisation, de communication et de résistance des prisonniers politiques, leurs relations avec les prisonniers de droit commun, les avantages et privilèges dont jouissaient parfois certains détenus et l'usage des réseaux d'amitié pour tempérer les effets de la répression. La conclusion met l'accent sur l'importance d'analyser la prison politique comme un élément central de l'évolution du parti apriste.

Mots-clés : APRA, prison politique, torture, résistance, répression, prisonniers de droit commun

* Una versión preliminar y más extensa de este ensayo fue presentada en el $53^{\circ}$ Congreso Internacional de Americanistas en México en julio de 2009.

** Profesor, Departamento de Historia, Universidad de Oregon, Eugene, OR 97403. E-mail: caguirre@ uoregon.edu 


\title{
Men and prison bars: APRA in the penitentiary, 1932-1945
}

\begin{abstract}
This article analyzes various aspects of the political imprisonment of Aprista leaders and militants between 1932 and 1945 and seeks to introduce some correctives in the official party version that tends to emphasize the heroism and sacrifice of those who suffered detention and mistreatment from authoritarian regimes. The article reviews the forms of organization, communication, and resistance on the part of political prisoners, their relationship with common criminals, the advantages or privileges that at times some of them enjoyed, and the use of networks of friendship to try to diminish the effects of political repression. The conclusion emphasizes the importance of studying political imprisonment as a central element in the evolution of the Aprista party.
\end{abstract}

Keywords: APRA, political imprisonment, torture, resistance, repression, common prisoners

Entre 1932 y 1945 miles de dirigentes y militantes apristas sufrieron cárcel y destierro y cientos de ellos encontraron la muerte a manos de sucesivos gobiernos autoritarios. La historia oficial aprista ha incorporado en su narrativa estas circunstancias dolorosas y las ha resaltado como hitos fundamentales no solo de la historia partidaria sino también de la historia peruana e incluso latinoamericana. Al hacerlo, no ha podido evitar incurrir en una cierta dosis de mitificación en función de la necesidad de crear una versión histórica que se ajuste a las necesidades partidarias. Este esfuerzo es parte de un proceso más amplio de recrear un pasado glorioso, mítico, fundacional que contribuyera a legitimar ante sus militantes, la opinión pública y los estudiosos de su trayectoria la conducta política del partido y sus dirigentes. Es frecuente encontrar exageraciones, distorsiones o silencios respecto a determinados aspectos de la historia partidaria. En el caso de la prisión política sufrida por miles de apristas la historia oficial pone de relieve el sufrimiento, la resistencia y la heroicidad de sus militantes: en este relato, ellos fueron víctimas de una represión brutal, padecieron condiciones carcelarias insufribles y se les sometió a terribles torturas. Pese a ello, y gracias a la mística y disciplina partidarias, así como al sentido de responsabilidad histórica y sacrificio por una causa justa, ellos pudieron sobrevivir y salir airosos de dicha «prueba». La experiencia de la cárcel habría sido para los apristas una escuela de lucha revolucionaria, una fuente de fortaleza para templar su carácter y una trinchera de combate contra los regímenes represivos y autoritarios de la cual salieron limpios y victoriosos.

En este ensayo se busca ofrecer una reconstrucción algo más compleja de la experiencia aprista en la prisión entre 1932 y 1945. Lo que puede llamarse «historia oficial» de la experiencia de la prisión —una narrativa que resalta el heroísmo y sacrificio de los militantes - no es del todo falsa pero sí incompleta. 
Usando documentos de archivo, testimonios individuales y textos literarios este artículo busca acercarnos al mundo de la prisión política para obtener una imagen más matizada de la experiencia carcelaria. Aunque se ha incluido información fragmentaria sobre la prisión de mujeres apristas, el grueso de la documentación y los argumentos centrales en este ensayo se refieren a la prisión política de apristas hombres. La escasa documentación y el número al parecer bastante reducido de mujeres apristas que sufrieron prisión impiden ofrecer una reconstrucción más amplia de su experiencia en la cárcel.

El estudio de la prisión política, como han demostrado numerosos estudios sobre sociedades tan distintas como Sudáfrica durante el Apartheid, la India durante el periodo de dominación británica, España durante el franquismo o los países del Cono Sur en tiempos de las dictaduras militares, por mencionar algunos ejemplos, permite la aproximación a una serie de problemas históricos. Estos incluyen, por ejemplo, los mecanismos de coerción y violencia ejercidos por regímenes represivos, las formas legales e ilegales que asumió dicha represión, la exclusión de amplios sectores de la población del disfrute de sus derechos políticos, la formación de culturas políticas de oposición, los mecanismos de organización y resistencia generados por los propios presos políticos, los aspectos culturales de la prisión (prácticas de escritura y lectura, por ejemplo), la formación de mitos y símbolos de heroicidad que amplifican y refuerzan las luchas de los militantes y, finalmente, las conexiones entre la prisión política y la estructura y funcionamiento de las organizaciones a las que pertenecían los militantes. En el caso peruano, es indudable que el estudio de la prisión política de militantes apristas durante los períodos 1932-1945 y 1948-1956 constituye un elemento central para entender tanto la trayectoria de dicho partido como la historia política del país en su conjunto¹.

\section{EL APRA EN PRISIÓN, 1932-1945²}

El Partido Aprista Peruano (PAP) fue fundado en septiembre de 1930. Poco antes, en julio de ese año, el dictador Augusto B. Leguía había sido derrocado por un golpe de Estado dirigido por el coronel Luis M. Sánchez Cerro, quien ejerció como presidente de facto por algunos meses y fue luego reemplazado por varios otros gobernantes provisionales, incluyendo a David Samanez Ocampo, quien convocó a elecciones el 11 de octubre de 1931. Víctor Raúl Haya de la Torre, dirigente máximo e ideólogo del partido y que había estado viviendo en el exilio desde 1923, regresó al Perú en julio de 1931 y poco después el PAP organizó su primer congreso que designó a Haya de la Torre como su candidato presidencial. Su principal rival fue el ex presidente Sánchez Cerro, líder del partido Unión

1 Véase Buntman (2003), Singh (1998), Molinero et al. (2003) y Calveiro (1998) sobre la prisión política en Sudáfrica, India, España y Argentina respectivamente. En Aguirre (2013), se han estudiado los aspectos culturales de la prisión política en el Perú del siglo XX.

2 En este ensayo se utiliza APRA, Partido Aprista Peruano y PAP indistintamente. 
Revolucionaria. Durante la campaña electoral, por tanto, se enfrentaron dos tipos de populismo con amplio arraigo popular, uno nacionalista y radical (APRA) y otro conservador y defensor del orden y el status quo (Unión Revolucionaria) (Stein, 1980). Sánchez Cerro era presentado por el APRA como el candidato de la oligarquía mientras que Haya de la Torre era visto por sus contendientes como un agitador comunista. Sánchez Cerro fue declarado ganador y el APRA denunció fraude, con lo que abrió el camino a diversas formas de resistencia contra un gobernante que era considerado por ellos como ilegítimo. En ese mismo proceso habría de elegirse representantes para una Asamblea Constituyente. El APRA obtuvo 27 curules de un total de 145 y, pese a las denuncias de fraude, decidió participar de la Asamblea Constituyente instalada el 8 de diciembre de 1931 (Giesecke, 2010: 94-108; Stein, 1980, passim; Murillo, 1976: 100-126).

A partir de diciembre de 1931 el clima de confrontación entre el APRA y el gobierno presidido por Sánchez Cerro se tornó progresivamente violento. Numerosas revueltas, protestas, asonadas, atentados, asesinatos y masacres fueron la traducción práctica de las crecientemente irreconciliables posiciones del gobierno de Sánchez Cerro y de la oposición aprista. El 8 de diciembre de 1931, el mismo día que Sánchez Cerro asumió la Presidencia de la República, Haya de la Torre pronunció en Trujillo un emotivo discurso que, de alguna manera, anticipaba la sombra oscura que estaba a punto de dejarse caer sobre el Perú:

Hoy comienza para los apristas un nuevo capítulo de la historia del Partido. Las páginas de gloria o vergüenza las escribiremos nosotros con sangre o con lodo (...) Yo estaré en mi puesto hasta el fin. Espero que cada uno de los apristas no abandone el suyo (Murillo, 1976: 131).

Conforme se acentuaba el clima de violencia numerosos militantes apristas eran detenidos arbitrariamente. Una Ley de Emergencia remitida por el ejecutivo fue aprobada por la Asamblea en enero de 1932 y autorizaba al Ejecutivo la toma de medidas radicales contra aquellos que perturbasen el orden público. A fines de febrero de 1932, la representación aprista fue desalojada de la Asamblea Constituyente y 23 de sus miembros fueron enviados al exilio. El 6 de marzo un joven aprista, José Melgar Márquez, atentó contra la vida de Sánchez Cerro cuando éste salía de una iglesia de Miraflores luego de asistir a misa. Melgar y Juan Seoane, este último juez y hermano del líder aprista Manuel Seoane, fueron detenidos, procesados y sumariamente condenados a muerte por el atentado. La pena de muerte contra Melgar y Seoane sería luego conmutada por 25 años de reclusión en la penitenciaría (Murillo, 1976: 157-175).

A partir de este momento se incrementó la represión contra el APRA y con ella el número de apristas encarcelados en todo el país. En Lima, la penitenciaría (conocida también como «el Panóptico» por su estilo arquitectónico), la isla penal de El Frontón, la prisión conocida como El Sexto, la Cárcel Central de Varones, la Intendencia de Lima, el castillo del Real Felipe en el Callao y varios otros establecimientos policiales y militares se vieron crecientemente colmados de presos apristas. También se usaron prisiones en el interior del país, incluyendo una en la Isla Taquile en Puno y la colonia penal de Satipo en la selva peruana. 
Muchos altos dirigentes apristas, incluído el propio Haya de la Torre, pasaron largas temporadas en la cárcel. El número de presos se incrementó aún más luego de la fracasada insurrección de Trujillo, ocurrida el 7 de julio de 1932 (Thorndike, 1973; Giesecke, 2010). Se instalaron Cortes Marciales para juzgar sumariamente a los implicados en dicha insurrección y se detuvo a un alto número de sospechosos. El Perú se convirtió, según expresión de Haya de la Torre, en «una inmensa prisión y en un gran patíbulo» (Murillo, 1976: 309). Los asesinatos de Sánchez Cerro el 30 de abril de 1933 y Antonio Miró-Quesada de la Guerra, director de El Comercio, y su esposa, María Laos, el 15 de mayo de 1935, ambos obra de militantes apristas, no hicieron sino exacerbar los ánimos e intensificar la represión. De hecho, en 1933, poco después del crimen contra Sánchez Cerro, el partido aprista fue ilegalizado bajo la acusación de que se trataba de un partido internacional.

En años sucesivos y hasta 1945, año en que el APRA recupera su legalidad plena, los vaivenes de la política nacional y las cambiantes estrategias que el partido aprista puso en marcha para tratar de contrarrestar la represión y abrir espacios de libertad (incluyendo insurrecciones, pactos políticos y participación electoral subrepticia) hicieron que la violencia contra el aprismo, si bien no fue del todo abandonada, atravesara por períodos de intensidad variada durante los períodos presidenciales de Oscar R. Benavides (1933-1939) y Manuel Prado (1939-1945).

¿Cuántos apristas pasaron por la cárcel durante estos años? Es muy difícil ofrecer una cifra concluyente. Un documento de denuncia firmado por presos de El Frontón en junio de 1935 hace referencia a los «más de 2000 apristas» que se encontraban en prisión por esa fecha3. En 1938, un artículo publicado por la revista Claridad de Buenos Aires calculaba que el número de presos políticos en el Perú «oscila entre los cuatro y cinco mil» (Murillo, 1976: 391). Un documento partidario sin fecha — aunque escrito con posterioridad a 1938 - titulado «Lista de condenados por las cortes marciales» incluye listas de sentenciados en Lima, Trujillo, Huaraz e Iquitos y a los que se hallaban en El Frontón o la penitenciaría, muchos de ellos condenados a 15 o más años de reclusión, así como una lista breve de «secuestrados en la penitenciaría» (se deduce que no tenían sentencia) que incluía a altos dirigentes apristas como Agustín Haya de la Torre, Carlos Manuel Cox, Ramiro Prialé y otros. Se ha contabilizado 71 apristas recluidos en la penitenciaría, entre sentenciados y secuestrados, pero en una sección titulada «Secuestrados en El Frontón» se afirma que hay 480 apristas en la isla4. Las listas oficiales de presos políticos en El Frontón para el año 1933, por otro lado, registran cifras que oscilan entre 57 y $186^{5}$. Entre ellos estuvieron numerosos dirigentes apristas de la más alta jerarquía, cuya captura tenía un doble efecto: por un lado constituía un golpe a la organización, que veía así demostrada su vulnerabilidad

3 Archivo General de la Nación (en lo sucesivo AGN), Ministerio de Justicia (en lo sucesivo MJ), Leg. 3.20.3.1.12.2.6, 1933-1934, El Frontón.

4 Archivo personal de Luis Heysen. Agradezco a Socorro Heysen por permitirme consultar este y otros documentos en el archivo de su padre.

5 AGN, MJ, Leg. 3.20.3.1.12.7, 27 de noviembre de 1934. 
y disminuida su fuerza organizativa en la clandestinidad; por otro lado, reforzaba la organización dentro de las prisiones, inyectando una cuota de moral partidaria a quienes estaban padeciendo la prisión, especialmente los militantes anónimos.

\section{LA PRISIÓN POLÍTICA: SUFRIMIENTO Y HEROICIDAD}

Dos elementos centrales destacan en las representaciones oficiales partidarias sobre la prisión política aprista: los horrores y sufrimiento infligidos a los militantes apristas y la entereza, sacrificio y heroicidad demostrados por ellos. El trato que recibían es presentado generalmente en términos universalmente negativos. «En las cárceles los presos políticos eran sometidos a crueles torturas», generaliza Murillo (1976: 179). Luis Heysen, uno de los más destacados dirigentes apristas de esos años, describió así la situación:

Las prisiones fueron lugares de suplicio y aislamiento brutales, en las que prácticamente, se condenaba a los seres humanos a sufrir no sólo los ultrajes morales y físicos del propio cautiverio, sino a no volver a tener más contacto con el mundo (Heysen, 1933: 19).

El manifiesto antes citado de 1938 reitera esta visión sufrida y atormentada de las condiciones carcelarias:

Hace siete años que se ahogan en sangre nuestras voces y que de sangre y dolor se hace huella de nuestro paso. La sangre y el dolor son ahora nuestro pan diario del presidio. Ni un día de tranquilidad, ni una hora de paz, ni un segundo de calma. Siempre sobre nosotros, el castigo cruel y la saña de la tortura moral (Murillo, 1976: 423).

Algunas prisiones, en particular El Frontón, el Panóptico y las colonias penales de Madre de Dios y Satipo, adquirieron en el imaginario aprista (y probablemente en el de amplios sectores de la sociedad peruana) una reputación —ciertamente más que merecida - como lugares de tormento y sufrimiento. En la penitenciaría, por ejemplo, según el manifiesto antes citado, «se vive un ambiente de inminente violencia»y los suicidios eran frecuentes (Murillo, 1976: 423). El mismo manifiesto de 1938 consideraba a El Frontón como «la prisión más terrible», donde «se tiene a los hombres semidesnudos y se les castiga a vergajazos». Había presos que morían por falta de atención y otros como resultado de los castigos y venganzas de las autoridades (Murillo, 1976: 424-425). En el local de la Intendencia de Lima, el trato a los presos fue descrito como «cruel e inhumano»6. Allí, en los calabozos de la Intendencia, se torturaba a los presos y se les obligaba a ejercitar tareas «denigrantes» como barrer las celdas y limpiar los baños. En la cárcel conocida como El Sexto los presos apristas ocupaban el segundo piso, «en unas celdas de cemento, sin catres ni mesas, en suma, sin mobiliario» donde permanecían sin ver

6 «Copia literal del informe del Dr. Dn. Carlos Alberto Izaguirre, diputado $3^{\circ}$ del Instituto, acerca de la situación de los presos político-sociales», 12 de junio de 1934 (AGN, MJ, Leg. 3.20.0.3.1.11.2). 
el sol ni respirar aire puro. Mención especial merecen los casos de las colonias penales de Madre de Dios y Satipo, adonde fueron enviados decenas de apristas. Juan Seoane llama a la primera la «Siberia de Fuego» y ofrece una descripción aterradora del traslado hacia ella y las condiciones que enfrentaban los detenidos (Seoane, 1937: 73-74). El aprista Miguel de la Mata dejó un testimonio sobre la colonia de Satipo:

La vida era un horror para nosotros. Trabajo forzado de once horas diarias bajo soles inclementes o lluvias inmisericordes, paludismo, torturas, trato inhumano (citado en Murillo, 1976: 440).

El uso de la tortura en estos centros de detención era casi siempre resaltado en los documentos de denuncia de los militantes apristas y, como es natural, también lo ha sido en las narraciones históricas y en las memorias y escritos literarios producidos, años después, por dichos militantes. Diferentes relatos se refieren a episodios en los que el uso de golpes, la picana eléctrica, el «cepo volador», la privación de agua, alimento y cuidado médico, y el aislamiento en lugares de castigo como «La parada» o «La lobera» en El Frontón y las celdas aisladas en el Panóptico eran infligidos cotidianamente a los militantes apristas. «La parada», según Luis Felipe de las Casas, «era un monstruoso ataúd u ornacina de cemento, incrustada en una pared de concreto armado, ubicado en la falda del cerro (...) que obligaba al castigado a estar parado sin poder sentarse ni recostarse» (De las Casas, 1981: 98). La «lobera», por su parte, fue descrita entre otros por el detenido aprista Bernuy Ortiz en una carta el Inspector General de Prisiones:

Es un socavón hecho por el mar en un acantilado del Frontón. En su fondo están las celdas de castigo. A las horas de creciente el mar chicotea las rocas, llegando hasta los presos ${ }^{7}$.

También existía un lugar de castigo conocido como la «sepultura», «la máxima expresión del refinamiento y la agudeza carcelaria como malvada intención de los directores (...) monumento a la bestialidad» (De las Casas, 1981: 99-100).

En el Panótico las condiciones eran igualmente opresivas. Un memorial firmado por presos comunes y políticos denunció en la prensa distintas formas de maltrato y hostigamiento (supresión de recreos, disminución de la ración de comida, utilización de frazadas de los presos como techos de los gallineros, la imposición de un régimen de «servidumbre» entre los presos a cambio de comida, la prohibición de lectura, etc.) y, en represalia, las autoridades castigaron a los firmantes enviándoles a «celdas subterráneas, oscuras, fétidas y húmedas»8. En una denuncia de los presos apristas de noviembre de 1937 se acusa al director, Eduardo Lanatta, de ser un «profesional de la persecución al aprista» (Murillo, 1976: 423-424).

7 AGN, MJ, Leg. 3.20.3.1.12.1.6.

8 «Copia literal del informe del Dr. Dn. Carlos Alberto Izaguirre, diputado $3^{\circ}$ del Instituto, acerca de la situación de los presos político-sociales», 12 de junio de 1934 (AGN, MJ, Leg. 3.20.0.3.1.11.2). 
Hubo muchos apristas que murieron como resultado de los maltratos en las prisiones: Víctor Manuel Peralta, un estudiante de 19 años, murió en El Frontón en febrero de 1935 a consecuencia de los maltratos y la falta de atención médica; el teniente Pineda Alcócer se suicidó en el Panóptico en 1936 al no poder resistir los maltratos; José de la Fuente Mendoza fue asesinado en El Frontón en mayo de 1937; un joven aprista de apellido Oviedo murió en El Frontón en fecha no precisada a causa de las torturas y deficiente alimentación. Varios otros presos apristas que padecían enfermedades graves murieron por falta de atención médica oportuna (Murillo, 1976: 407-408).

No hace falta ofrecer más detalles de las condiciones frecuentemente inhumanas, humillantes e insalubres en que transcurrían los días en prisión para los militantes apristas. Estas condiciones, sin embargo, no lograron doblegar los espíritus de los detenidos, si nos ceñimos a la versión oficial de la historia. Murillo resume esta visión heroica de la resistencia aprista a las condiciones carcelarias:

Pese a todas las torturas y padecimientos es un hecho comprobado que la moral de los apristas se mantuvo muy alta en las prisiones. (...) Los apristas supieron afrontar este calvario con entereza y coraje, cerrando filas dentro y fuera de las prisiones en una lucha desigual (Murillo, 1976: 426, 440).

La resistencia a la adversidad aparece, en este discurso, motivada y sostenida por la esperanza del triunfo del aprismo y la fe en las ideas que profesaban ${ }^{9}$. Se cita el caso del preso J. Santos Rujel Díaz, quien ofrecería su testimonio poco después de que el partido recuperase su libertad plena en 1946:

Tenemos el cuerpo destrozado por tantos días de hambre, de sed, de vigilia, de tortura y reímos y cantamos nuestro himno de fe. Qué maravillosos milagros opera la fe en la vida del hombre. Nosotros sufrimos y vivimos nuestro ideal y nuestra fe, y creemos que de los surcos sangrantes de nuestro dolor surgirá la aurora de un nuevo día de justicia (Rujel Díaz, 1946: 16).

Un elemento central detrás de esta fortaleza política y espiritual que parecían tener los presos apristas lo constituía la comunicación entre ellos (un tema que se retomará más adelante) y los mensajes recibidos desde fuera, especialmente de su líder máximo Haya de la Torre. Sus mensajes a los presos políticos, dice Murillo, constituían «documentos de orientación y adoctrinamiento, de aliento y de estímulo contagiantes» (Murillo, 1976: 426). Haya de la Torre sufrió quince meses de prisión, con frecuencia en aislamiento total, entre 1932 y 1933 (Thorndike, 1973: 108; Murillo, 1976: 185-186). Se formó un movimiento internacional para salvarle la vida, pues luego de la rebelión de Trujillo se temía que fuera ejecutado por el régimen de Sánchez Cerro (Murillo, 1976: 196-199; Partido Aprista Peruano, 1933: 147-183). Según Luis Alberto Sánchez, un preso común, Adolfo Riojas, se

9 La dirigente aprista y poeta Magda Portal ofreció una versión de esta mística partidaria en poemas como «Cárceles, vastos cementerios» y «Penitenciaría de Lima» (Portal, 1945). 
encargaba de probar la comida de Haya para evitar que lo envenenen (Sánchez, 1979: 222). Haya de la Torre sostuvo una huelga de hambre que tuvo sus frutos, pues las condiciones mejoraron levemente: se le permitió recibir lecturas —si bien censuradas - pero le estaba prohibido escribir y recibir cartas. Luego del asesinato de Sánchez Cerro, ocurrido el 30 de abril de 1933, se le permitió incluso recibir visitas (Murillo, 1976: 302). Meses después, el 10 de agosto de 1933, fue puesto en libertad, al igual que la mayoría de presos apristas, gracias a una ley de amnistía dictada por el gobierno provisional.

Haya de la Torre había experimentado en carne propia, por tanto, el dolor, el aislamiento y la angustia de la prisión política, y esto se ve reflejado en las cartas que escribió a los presos apristas y que fueron editadas por el dirigente aprista Carlos Manuel Cox (1946). Las cartas contienen palabras de aliento, recomendaciones para sobrevivir en la prisión, mensajes de reafirmación partidaria, la exaltación del heroísmo de los presos y mártires apristas, un énfasis en la necesidad del sacrificio para conseguir sus objetivos y la reiteración de que tarde o temprano la victoria les sonreiría y culminarían su misión histórica.

Todos ustedes - escribe en una carta a los presos del Panótico en marzo de 1936 - están acumulando, con su sacrificio en la prisión, títulos honrosos para el Partido. Las amarguras y privaciones que ustedes pasen no son experiencias baldías. Antes bien, así aumentan la gloria del Aprismo y su creciente autoridad moral sobre las masas ciudadanas del país (Cox, 1946: 45, énfasis agregado).

Constantemente se refiere Haya de la Torre a conceptos como deber, sacrificio, moral, constancia, valor, y casi siempre busca trasmitir a los detenidos la convicción de que la gesta aprista nacía de una justificación histórica que la hacía necesaria. La visión mesiánica y religiosa de Haya y del APRA que muchos estudiosos han resaltado (y que los apristas mismos jamás han negado) alcanza niveles líricos en algunos pasajes de estas cartas:

Hemos sufrido y estamos sufriendo, pero jamás nos hemos dejado dominar por la desesperación cobarde o por el decaimiento, indignos de nuestra santa causa. Todas las grandes revoluciones han tenido épocas parecidas a la nuestra. La historia está llena de ejemplos de largos sufrimientos y de prolongadas, dolorosas y desalentadoras esperas. Pero es justamente en tales momentos en los que el hombre pone a prueba su moral y su lealtad, su idealismo y su responsabilidad (Cox, 1946: 77).

Al mismo tiempo que intentaban trasmitir un mensaje de fe y esperanza a los militantes apristas, las misivas de Haya de la Torre buscaban inculcar en ellos una clara idea de la disciplina partidaria, tratando así de asegurarse que la cárcel se convirtiese en un espacio de formación de militantes. Una de las prioridades era, naturalmente, el respeto a las jerarquías partidarias, y Haya de la Torre no perdía oportunidad de enfatizarlo:

Para ser oficial hay que ser buen soldado. Sólo sabe mandar quien supo obedecer. (...) Sólo así, isólo así! se es buen aprista, comprendiendo y 
haciendo comprender esto, renovando la fe en nuestra causa y la fe en nuestros jefes (Cox, 1946: 31-32, énfasis agregado).

En otra carta Haya de la Torre les pide a los presos de la penitenciaría:

Recuerden que la dirección del partido sigue en manos de compañeros firmes y leales que todo lo sufren y todo lo soportan por alcanzar la victoria. En una palabra, tengan fe... (Cox, 1946: 47).

Sin duda Haya de la Torre estaba tratando de combatir el desánimo pero también la posible percepción de que los dirigentes del partido estaban alejados del sufrimiento de los presos, gozaban de cierta comodidad en la libertad o el destierro y/o se estaban desviando de sus principios ideológicos (algo que, se sabe muy bien, estaba siendo ya cuestionado por algunos militantes apristas) (Manrique, 2009). Las cartas de Haya incluían también recomendaciones muy precisas sobre cómo afrontar la experiencia de la prisión, enfatizando el trabajo intelectual, la disciplina y el ejercicio físico (Cox, 1946: 48, 54, 63).

Algunas cartas de Haya de la Torre trasmitían un exagerado optimismo sobre el futuro del partido. Esto se explica, naturalmente, por la necesidad de inyectar dosis de esperanza para combatir el desaliento, la frustración e incluso quizás el descontento. En una carta del 7 de julio de 1938 (aniversario de la rebelión de Trujillo), Haya de la Torre decía a los presos:

El Aprismo está cobrando cada día una importancia mayor en el continente»(Cox, 1946: 56).

En otra carta les dice, con evidente hipérbole:

Ustedes, los prisioneros apristas, están atrayendo cada vez más la admiración general. En cada hora del día, en cada lugar del Perú, en cada calle, en cada grupo, se habla o se piensa en ustedes (Cox, 1946: 63).

En noviembre de 1939 reitera:

El Aprismo está más fuerte y más unido que nunca, y su ejemplo heroico de cinco años (...) es un título de gloria sin precedentes en el Perú (Cox, 1946: 83).

Por otro lado, Haya de la Torre insistía en que los militantes en prisión debían prepararse para cuando llegase el momento de la libertad o la victoria:

Procuren salir tranquilos y sanos, aptos para reincorporarse a la vida con fe, sin amargura, dejando atrás todo lastre negativo, como se dejan los despojos de las batallas sangrientas, y salvando únicamente el viril orgullo de haber cumplido ampliamente con su deber (Cox, 1946: 86).

Y vuelve a insistir en el rol de los dirigentes, especialmente el suyo:

Hago todo lo posible para que cuando ustedes salgan vean que no hemos escatimado esfuerzo alguno en la conservación y mantenimiento de nuestra maravillosa obra (Cox, 1946: 88).

Haya de la Torre fue un líder que supo interpretar, en distintos momentos de la historia peruana, los sentimientos y expectativas de amplios sectores de la población y edificó un partido disciplinado y moderno pero que también apelaba 
a la mística casi religiosa de la militancia. Las cartas que escribió a los presos apristas reflejan esa dedicación obsesiva a la tarea de afianzar la organización partidaria, asegurarse la lealtad de los militantes y crear una mística que les permitiese no sólo sobrevivir a la adversidad con la mirada puesta en un futuro resplandeciente para todos, sino también aceptar las decisiones de los dirigentes, pues fueron adoptadas pensando en los beneficios para el partido y para el país. Del sufrimiento a la resistencia pasando por la fe y la mística: así se construyó el círculo que hizo que los miles de apristas que sufrieron encierro por causa de sus ideas y acciones decidieran luego continuar apoyando al partido lealmente pese a los giros tácticos e ideológicos que se producirían en más de una ocasión. La cárcel templó el carácter de estos militantes, pero también, de alguna manera, los preparó para una vida partidaria que priorizaría la lealtad y la disciplina antes que la actitud crítica y cuestionadora de ciertas decisiones y prácticas políticas.

\section{DISCIPLINA, ORGANIZACIÓN Y RESISTENCIA}

Los apristas eran militantes de un partido altamente estructurado y disciplinado, y no sorprende por ello que en la cárcel demostraran una fuerte tendencia a la organización y la disciplina. De todas las prisiones que albergaron presos apristas, El Frontón, el Panóptico, la Cárcel Central de Varones y El Sexto eran las que más auspiciaban esta organización. En El Frontón los presos apristas — salvo aquellos sometidos a aislamiento por castigo- pasaban largas horas del día no solo juntos sino fuera de los pabellones de reclusión y prácticamente sin vigilancia directa. En las otras prisiones, el contacto directo era más esporádico (durante las horas de patio o de comidas) pero no por ello menos eficaz. El contacto entre presos contribuía a reforzar la disciplina y la moral partidarias, y permitía además ejercitar formas de resistencia como motines, protestas colectivas y la redacción de manifiestos y proclamas. La transmisión de información era también mucho más efectiva en estos casos.

Los presos apristas creaban comités — por cuadra o por piso, dependiendo de la prisión-y se designaban delegados encargados de atender asuntos como la salud, la alimentación, la educación y la lectura. Gracias a esta organización celular se regulaban detalles cotidianos como el uso de los servicios higiénicos o las tareas de limpieza, pero también otras actividades de carácter partidario e intelectual (De las Casas, 1981: 92; Villanueva del Campo \& Thorndike, 2004: 55). Los presos apristas también solían organizar lo que se llamó la «Universidad Popular González Prada» —inspirada en la escuela obrera del mismo nombre organizada por Haya de la Torre a comienzos de la década de 1920 - con la finalidad de aprovechar el tiempo disponible y mantenerse intelectualmente activos. También aquí la disciplina, organización y jerarquías se hacían evidentes: se escogía rector y decanos y se designaba a los profesores, quienes se encargarían de dar clases en diversos temas según su especialidad (Villanueva del Campo \& Thorndike, 2004: 55). En la cárcel de mujeres «la vida de la celda queda organizada como una célula unionista, con su horario pre-establecido» (Portal, 1957: 53). 
Como era de esperarse, hubo múltiples formas de resistencia a la autoridad por parte de los presos apristas, algunas de ellas soterradas y silenciosas y otras abiertas y frontales. En esto, la conducta de los presos apristas no se diferenciaba mucho de aquella mostrada por presos políticos en otras latitudes o, más generalmente, por distintos grupos de personas sometidas a regímenes de opresión y sometimiento. Eran frecuentes los insultos y desafíos verbales a guardias y autoridades, incluyendo el canto de la marsellesa aprista dentro de las celdas, lo que solía hacerlos merecedores de castigos como el aislamiento, la prohibición de visitas e incluso el traslado de una cárcel a otra10. También hicieron un uso constante, en la medida que lo permitían las circunstancias, de la redacción de cartas de protesta y denuncia, como la que escribió el preso aprista Jorge García Mendizábal en septiembre de 1935 al director de la penitenciaría para reclamarle que «se ensañe cobardemente conmigo quitándome derecho a mis visitas, descargando en esa forma, contra mí, una venganza poco honorífica» y le recuerda que «los pueblos avanzan en medio de la sangre y no se manchan cuando se dirigen a la conquista de los derechos, a la justicia y a la libertad del hombre». Más importante aún, proclama con orgullo que es un preso político y que su «falta» (es decir, su militancia) es castigada por el hecho de ser un derrotado temporal pero que el futuro sería muy diferente 11 . La retórica es muy reveladora del estado de ánimo, la mística partidaria y el grado de convicción que caracterizaban a muchos militantes apristas: la defensa de sus derechos, el carácter justo y sagrado de su lucha y la certeza en la futura victoria. García Mendizábal sufriría severas represalias por su actitud desafiante. Al lado de misivas individuales como esta también se redactaban y hacían circular manifiestos colectivos dirigidos a las autoridades de las prisiones, los militantes del partido o los medios de comunicación. El 10 de diciembre de 1934, por ejemplo, «los detenidos políticos y sociales» de El Frontón solicitaron al director una entrevista para plantearle un pliego de reclamos que incluía distintos tipos de demandas relacionadas con la salud y la vida cotidiana de los presos, desde la mejora de la alimentación y la atención médica hasta la entrada libre de periódicos12. En noviembre de 1937 los presos apristas redactaron un largo mensaje «a los trabajadores del continente» para denunciar «la tragedia que (...) se nos hace vivir» y exigían «que cese el espectáculo de vergüenza con que se enloda a América» y que «se humanice el trato de los detenidos y rematados político-sociales» (Murillo, 1976: 423)13.

La huelga de hambre fue un recurso de protesta empleado en numerosas ocasiones, a veces individualmente (como el caso de Haya de la Torre antes mencionado) y con mayor frecuencia en forma colectiva. El dirigente aprista Rómulo Meneses,

10 AGN, MJ, Leg. 3.20.3.1.12.1.5, 20 de febrero de 1934.

11 AGN, MJ, Leg. 3.20.3.1.12.1.5.

12 El documento aparece firmado por los miembros de «La comisión», incluyendo a Pedro Blak (o Black), un chofer y dirigente sindical aprista que encontraría la muerte años después, en 1945, como resultado de los maltratos y torturas a los que fue sometido (Murillo, 1976: 438).

13 Los archivos de la Dirección General de Prisiones contienen otros manifiestos similares (AGN, MJ, Leg. 3.20.3.1.12.2.6, 1933-1934, El Frontón). 
en un texto escrito en la cárcel en diciembre de 1932, consideraba la huelga de hambre «una medida extrema, heroica y formal a la cual suelen y deben apelar los prisioneros político-sociales, en circunstancias desfavorables» (Meneses, 1933: 93-94) pero advierte que su utilización debe tener en cuenta «la responsabilidad que con tal acción se incurre ante la disciplina del partido» (Meneses, 1933: 97). No es posible determinar cuántas y cuáles de las huelgas de hambre que se han documentado fueron coordinadas con las más altas instancias partidarias, pero el grado de organización y disciplina que requerían sugiere que en efecto, a diferencia de iniciativas individuales, ellas fueron resultado de decisiones partidarias. El 16 de junio de 1932, por ejemplo, en una carta al director de El Frontón, los presos apristas anunciaban el comienzo de su huelga de hambre «como justa protesta por la arbitrariedad que en todo momento se ha procedido apresando infinidad de ciudadanos» ${ }^{14}$. El 31 de enero de 1933, los presos apristas se declararon nuevamente en huelga de hambre y volvieron a redactar un comunicado dirigido a las autoridades de El Frontón:

Huelga de hambre indefinida por la liberación de todos los presos políticossociales de la nación. La renuncia a los alimentos o sea la renuncia a la vida que como máximo sacrificio nos impone por conseguir nuestra libertad queda en manos de Ud. como responsabilidad única dentro de esta trágica situación 15 .

El 27 de julio de ese mismo año los presos de El Frontón, «de distintas filiaciones» (había presos apristas y comunistas entre ellos) se declararon una vez más en huelga de hambre pidiendo su libertad y la de los detenidos en las demás prisiones ${ }^{16}$. También las mujeres de Santo Tomás utilizaron esa medida de fuerza (Seoane, 1937: 153).

Por otro lado, hubo innumerables intentos de fuga, tanto del Panóptico como de El Frontón y varias otras prisiones. El aprista García Mendizábal, mencionado anteriormente, intentó fugar de la penitenciaría en mayo de 1936 y fue castigado con parada y un mes de aislamiento, para luego ser trasladado a El Frontón, donde pasó directamente a la «parada» y luego a la «lobera»17. José de la Fuente Mendoza, detenido en El Frontón, intentó fugar en la madrugada del 15 de mayo de 1937, pero fue baleado por las tropas encargadas de la custodia del penal (Murillo, 1976: 430). En 1938, cuatro apristas intentaron también fugarse de la isla penal: según la versión de un testigo, dos de ellos murieron ahogados y dos lograron llegar a tierra firme (Murillo, 1976: 433). Otro grupo de cuatro apristas lograron fugarse de El Frontón en junio de 1941 utilizando la lancha del mismo director del penal, aunque tuvieron que completar el último tramo a nado (Murillo, 1976: 437-438). Héctor Pretel logró fugarse de la penitenciaría en septiembre de 1935,

\footnotetext{
14 AGN, MJ, Leg. 3.20.3.1.12.2.6, 1933-1934, El Frontón.

15 AGN, MJ, Leg. 3.20.3.1.12.2.6, 1933-1934, El Frontón. Énfasis agregado.

16 AGN, MJ, Leg. 3.20.2.1.80.

17 AGN, MJ, Leg. 3.20.3.1.12.1.6.
} 
aunque fue luego recapturado. Varios apristas lograrían también fugarse de la temible colonia penal de Satipo, según testimonio de Miguel de la Mata recogido por Percy Murillo (Murillo, 1976: 441).

Ninguna forma de organización y resistencia colectiva habría sido posible sin el empleo de mecanismos ingeniosos y eficaces de comunicación entre los detenidos y entre ellos y el exterior de las cárceles. Un reporte sin fecha (aparentemente de mediados de la década de 1930), detalla los mecanismos usados por los presos apristas para comunicarse con el exterior: la escritura de cartas en clave; la colocación de cartas en paquetes de ropa sucia (en realidad, «inmunda» para que el «asco» impida a los agentes registrarla) que eran enviadas al exterior para ser lavadas; y cartas escritas en una tinta conocida como «simpática», hecha de limón y que al parecer permitía ocultar el texto y ser revelado posteriormente por el destinatario ${ }^{18}$. La forma más habitual consistía en utilizar a presos comunes y «caporales» (presos que tenían ciertas responsabilidades logísticas dentro de las cárceles) para hacer circular información verbal y escrita dentro y fuera de las prisiones. El peluquero de la penitenciaría, por ejemplo, entregaba volantes a algunos presos apristas (Seoane, 1937: 266). Esta práctica tenía naturalmente sus riesgos, pues existía siempre la posibilidad de que los presos comunes actuaran como soplones de las autoridades, pero con frecuencia era la única manera de mantener abierta la comunicación entre militantes y dirigentes, un elemento central en los esfuerzos por mantener la disciplina y la organización partidarias. El propio Haya de la Torre, durante su aislamiento, logró comunicarse con otros detenidos apristas tanto en el Panótico como en otras prisiones. En su novela Hombres y rejas, Juan Seoane narra uno de estos episodios:

Le comunico a Víctor Raúl lo que sé. Víctor Raúl trabaja infatigable. En la envoltura de cajetillas de cigarros me escribe ordenando la propaganda en Lima. Grandazo y Chorote [dos presos comunes, CA] la hacen salir retrasmitida por nosotros (Seoane, 1937: 221).

También se usaban las letrinas para intercambiar mensajes escondidos dentro del papel sucio (Villanueva del Campo \& Thorndike, 2004: 131); se enviaba correspondencia y otros objetos a través de las vías de desagüe, tarea generalmente encomendada a presos comunes dispuestos a hacerla a cambio de propinas u objetos materiales; también los presos comunes se encargaban de transportar documentos e información de una celda o pabellón a otro. Gracias a esto circulaban volantes, panfletos y revistas, algunos producidos dentro de las propias prisiones. En diciembre de 1937, por ejemplo, se encontró en los bolsillos de Sebastián Ahumada Pereyra, preso en la Cárcel Central de Varones, una serie de documentos partidarios, incluyendo una especie de boletín titulado «Cuaderno Aprista» y un volante titulado «Una moral sin dogmas» destinado a fortalecer la disciplina y la moral de los detenidos ${ }^{19}$. Los presos apristas escribían

18 «Documentos del P.A.P. Cartas Confidenciales. 1930-32-33-34-35 y 1937», Ministerio de Interior, Prefectura de Lima, Leg. 3.9.5.1.15.1.14.1

19 AGN, MJ, Leg. 3.20.3.1.12.5.4. 
y circulaban varios tipos de documentos, incluyendo cartas, volantes, mensajes e incluso periódicos, como fue el caso de uno titulado «El Frontón» que, según Blasco Bazán Vera, «se hacía a mano pero bellamente diagramado y contenía expresivos dibujos». Otro informativo partidario escrito en la cárcel se llamaba «La estrella» y también se menciona otros que trataban estrictamente de temas deportivos y sindicales (Bazán Vera, 2005). En El Sexto, en la década de 1930, dos presos apristas, José Barreto González y Luis Negreiros, escribían y hacían circular una publicación satírica titulada «El piojito» que, según relata Ricardo Temoche, «combatía la debilidad, el oportunismo, la cobardía» (Temoche, 1955: 15-16).

Las formas de resistencia y los mecanismos de supervivencia de los presos apristas eran muy variados y tenían diversos grados de éxito. En general, sin embargo, puede afirmarse que las formas de comunicación y escritura, la organización de células, las formas de protesta individual y colectiva, la organización de huelgas de hambre y otros mecanismos parecidos contribuyeron en gran medida a reforzar la militancia y la disciplina partidaria. La producción y circulación de volantes, cartas, manifiestos y periódicos resultó crucial para mantenerse informados sobre los sucesos de la política nacional y partidaria y para reforzar la moral y disciplina de los detenidos.

\section{PRESOS POLÍTICOS Y PRESOS COMUNES}

En otros trabajos se ha abordado el tema de las relaciones entre presos políticos y presos comunes (Aguirre, 2001; 2005). De todos los temas tratados en este ensayo, éste es probablemente el que menos espacio ocupa en las narrativas oficiales, salvo en los casos en que se denuncia que los presos políticos eran hostilizados colocándolos en celdas compartidas con presos comunes (lo que es cierto) y que estos eran vistos con desconfianza pues solían ser «soplones» de las autoridades (lo cual también es cierto). Según el informe ya citado de Carlos Alberto Izaguirre, cuando las autoridades de El Sexto deseaban castigar a los presos políticos los obligaban a compartir la celda con los vagos y eran efectivamente tratados como tales. Otros presos políticos eran retenidos en los calabozos de la Intendencia, donde compartían el espacio con rateros y vagos y eran sometidos a un trato humillante que incluía frecuentes aniegos de las celdas, lo que obligaba a los presos a dormir sobre un suelo mojado. La mala comida, los frecuentes insultos y otros aspectos degradantes de la detención fueron denunciados por Izaguirre ${ }^{20}$. Para Luis Felipe de las Casas, encarcelado en la Intendencia en 1934 después de una fallida conspiración contra el gobierno, resultaba ofensivo que se les agrupara junto con «dos clases de roedores [esto es, las ratas y los rateros, CA], cuáles más repugnantes», una situación que De las Casas consideraba «indigna de nuestra

20 «Copia literal del informe del Dr. Dn. Carlos Alberto Izaguirre, diputado $3^{\circ}$ del Instituto, acerca de la situación de los presos político-sociales», 12 de junio de 1934 (AGN, MJ, Leg. 3.20.0.3.1.11.2). 
condición de gente decente y de ser detenidos por motivos políticos» (De las Casas, 1981: 41, énfasis agregado).

La distancia social y cultural entre los presos políticos y los presos comunes era una realidad generalmente tangible y los primeros se encargaban de reforzarla y exigir una separación entre ambos grupos. Las descripciones que hacen los ex presos apristas de los presos comunes revelan prejuicios raciales y sociales muy marcados (De las Casas, 1981: 40; Seoane, 1937: 136). Las presas comunes representan para Marilú, el alter ego de Magda Portal, «extraños rostros» y su compañera de celda ofrecía «un aspecto tan repugnante»: «los pelos hirsutos le caen sobre la cara, sucios guiñapos cubren su esmirriado cuerpo» (Portal, 1957: 38).

La relación ambigua con los presos comunes - por un lado, una repugnancia y sentimiento de superioridad hacia ellos; por otro, una cierta necesidad de aliarse con ellos y/o mostrar algún tipo de solidaridad hacia su causa- produjo dos tipos de situaciones. Hubo numerosas ocasiones de colaboración e incluso proselitismo entre presos comunes y presos políticos. Un ejemplo es el caso del detenido indígena Mitay, quien estaba a cargo de servirle la comida a Haya de la Torre y que habría ofrecido a Juan Seoane llevarle recados suyos al «jefe» (Seoane, 1937: 118). Dos presos comunes, «Chorote» y «El Grandazo», como se ha visto, ayudaban a los apristas a conseguir cigarrillos y a enviar propaganda y comunicaciones hacia el exterior de la penitenciaría (Seoane, 1937: 221, 228). Un preso común le hacía llegar a Juan Seoane papel y lápiz para que escribiera cartas y le ofreció también traerle periódicos (Seoane, 1937: 34). Otro caso fue el de «Caldito Segundo», un preso común en el Panóptico cuya cercanía con los apristas constituía para el director un serio peligro, por lo que fue trasladado a El Frontón21. Según las autoridades los presos apristas desplegaban una agresiva campaña de proselitismo entre los presos comunes. En febrero de 1934, por ejemplo, el director de la penitenciaría se quejaba de la insubordinación de los presos apristas, quienes pretendían envolver dentro de esta conducta a los reclusos por delitos comunes22. Luis Chanduví, un preso aprista que fue enviado al Frontón por hallársele «documentación subversiva», regresó a la penitenciaría donde «viene desplegando actividad, haciendo propaganda aprista, pretendiento nuevamente constituir una célula y tratando de conseguir adherentes entre los reclusos comunes, para subvertir el orden en este penal» 23 .

Estas formas de cooperación y proselitismo produjeron formas colectivas de organización como motines coordinados, manifiestos de presos políticos que incluían reclamos a favor de los comunes y otras formas de acción común (Aguirre, 2005). Según Percy Murillo, «hubo casos de conversión de delincuentes que se rehabilitaron dentro del penal y se adhirieron a los ideales apristas con profunda convicción» (Murillo, 1976: 420). Villanueva del Campo agrega que el contacto

21 AGN, MJ, Leg. 3.20.3.1.12.1.6, 21 de diciembre de 1936.

22 AGN, MJ, Leg. 3.20.3.1.12.1.5, 20 de febrero de 1934.

23 AGN, MJ, Leg. 3.20.3.1.12.1.5, 13 de Junio de 1935. 
con los presos comunes ayudó a la «regeneración» de algunos de ellos (Villanueva del Campo \& Thorndike, 2004: 132).

En estas distintas formas de interacción ambos grupos obtenían alguna ventaja. La colaboración de los presos comunes no estaba siempre motivada por simpatías políticas, sino que era comprada con dinero o servicios, como por ejemplo la redacción de escritos judiciales por parte de presos apristas (Villanueva del Campo \& Thorndike, 2004: 132). Y esta relación de clientelismo se trasladaba también a la vida cotidiana. Los presos políticos pagaban a los presos comunes para que les cocinaran o les lavaran la ropa (Villanueva del Campo \& Thorndike, 2004: 182). Y en ocasiones, los presos comunes eran asignados casi como sirvientes a los presos políticos, lo que generaba relaciones de dependencia y a veces tensiones. Uno de ellos le reclamó a Juan Seoane en los siguientes términos:

Ud. especialmente ha confundido mi misión con el deber de servirlo a Uds. hasta en caprichos [...] iMe llaman para todo, señor Director! (Seoane, 1937: 208).

Para algunos intelectuales y presos políticos, los delincuentes comunes - algunos de ellos desesperados por conseguir dinero para comer o consumir coca- estaban allí para desempeñar las funciones de sirvientes domésticos.

Pero siempre flotaba la duda entre los presos políticos sobre las verdaderas intenciones de los presos comunes, especialmente la posibilidad de que se trate de infiltrados o soplones de las autoridades. La desconfianza hacia los comunes era, por necesidad, un mecanismo de defensa de los presos políticos. Las autoridades, de hecho, buscaban generar fricciones entre los dos grupos y azuzaban a los presos comunes a mostrar conductas hostiles hacia los políticos como una forma de mantenerlos separados y también para hacerles la vida más difícil a estos últimos (Murillo, 1976: 423).

La experiencia de la prisión política estuvo fuertemente marcada por estas relaciones. Para la mayoría de los presos apristas — especialmente aquellos que venían de familias de clase media «decentes», pero también para militantes de extracción popular- el contacto con los presos comunes debió ser uno de los desafíos más importantes que debieron afrontar al ingresar a la prisión. Juan Seoane lo expresó con total sinceridad cuando notó la manera tan dramática como su vida cambió cuando ingresó en prisión: «Chocan mis hábitos de clase media educado en colegio «decente», pulido y limpio como hijo de pequeño burgués, con el revoltijo de las dos cacerolas (...) Todo yo estoy sucio (...) iQué cambio tan violento de vida en unas horas!» (Seoane, 1937: 22-23).

\section{LOS PRESOS POLÍTICOS Y SUS PRIVILEGIOS}

Los presos políticos, pese a todo, no eran siempre los peor tratados dentro de las prisiones, y de hecho gozaban en ocasiones de ciertos privilegios. No se trata de negar las torturas, los castigos, las privaciones y todo lo que traía consigo el hecho de estar preso por sus ideas y acciones políticas. Pero — como ha sucedido en 
otras sociedades - ciertos presos apristas gozaron, en determinados momentos, de concesiones y privilegios derivados de contactos previos o recientemente establecidos y de su condición de miembros de las clases medias, decentes y letradas. Las propias autoridades reconocían y sancionaban estas distinciones, al menos retóricamente. El 30 de marzo de 1932, por ejemplo, el director de El Frontón reportó el ingreso de una docena de presos políticos que «han sido instalados $i$ atendidos de acuerdo a su condición social, pese a las deficiencias de todo orden con que se tropieza a cada momento»24. Según algunos documentos, las raciones de los presos políticos eran mayores que las de los presos comunes (lo que no significa, naturalmente, que fueran sustancialmente mejores o que todos quedasen satisfechos)25. Los contactos personales y hasta familiares con personajes influyentes e incluso con funcionarios de los gobiernos de turno podían, en ocasiones, traducirse en acciones que beneficiaban a los detenidos apristas, en algunos casos mejorando sus condiciones (permitiendo visitas que les trajeran comida, utensilios, materiales de lectura) y, en otros, trasladándolos a mejores celdas, pabellones o incluso prisiones que eran vistas como menos inclementes. El Director General de Prisiones, por ejemplo, había sido compañero de estudios de Juan Seoane y, pese a estar éste incomunicado, le permitió ver a su madre y esposa (Seoane, 1937: 229). El dirigente aprista Luis Rodríguez Vildósola era tratado con cierta benevolencia por la policía, según Villanueva del Campo, pues su padre era Mayordomo de la Hermandad del Señor de los Milagros, «a la que pertenecían muchos soplones» (Villanueva del Campo \& Thorndike, 2004: 128). El 20 de diciembre de 1937, por citar otro ejemplo, se halló propaganda al detenido aprista Sebastián Ahumada Pereyra, pero por «deferencia especial»solicitada por el Director General de Prisiones, fue colocado en la enfermería y se permitió la visita de su esposa26). El caso de Magda Portal también es revelador: el trato que le dieron mejoró mucho debido a que la madre superiora encargada de la prisión era hermana de una ex compañera de colegio suya (Reedy, 2000: 202).

Algunos presos políticos lograban evitar la tortura física entendida como el ejercicio de violencia directa contra el cuerpo de los detenidos: golpes, picana eléctrica, colgaduras y otras formas semejantes de castigo. Aunque esta forma de maltrato constituye, como se ha visto, un aspecto central de la narrativa heroica, es pertinente anotar que muchos dirigentes apristas nunca fueron sometidos a sesiones de tortura. Fue el caso de Haya de la Torre, por ejemplo, pero también de otros dirigentes como Armando Villanueva del Campo: «A mí nunca me tocaron», me dijo enfáticamente en una entrevista sostenida el año 2000. ¿Verdad o invención? En todo caso, el testimonio revela una cierta distinción en el trato a los dirigentes y los militantes, algo que se ha dado también en otros casos de

${ }^{24}$ AGN, MJ, Leg. 3.20.3.1.12.2.6, 1933-34, El Frontón, énfasis agregado.

25 AGN, MJ, Leg. 3.20.3.1.12.2.6, 1933-34, El Frontón.

26 AGN, MJ, Leg. 3.20.3.1.12.5.4. 
represión y encarcelamiento político. Cuando Juan Seoane recibió la visita de su hermano mayor y éste le pregunta si lo han torturado, la respuesta fue negativa (Seoane, 1937: 43).

\section{NEGOCIACIÓN: EL OTRO LADO DE LA RESISTENCIA}

Algunos de estos «privilegios» eran el resultado de gestiones — generalmente individuales - que hacían algunos detenidos o sus familiares respecto a las condiciones de su encarcelamiento. Es decir, se buscaba la «solución» a algún problema concreto usando no los canales partidarios y de resistencia política que se han explorado anteriormente — huelgas de hambre, por ejemplo- sino gestiones personales y relaciones de amistad. No se trata de «desacreditar», por así decirlo, estas acciones, ni de sugerir que los presos políticos no deberían haber usado estas tácticas. Pero es importante resaltar el hecho de que, en la medida que no calzan con la narrativa heroica, este tipo de gestiones y favores no encuentran cabida en las historias oficiales de la prisión política aprista, salvo en casos aislados de testimonios individuales.

Cuando Ciro Alegría fue detenido en el Panóptico en noviembre de 1932, por ejemplo, logró que lo cambiaran a una celda menos húmeda y le dieran un colchón mejor que el que le había tocado. El inspector, disgustado por tener que satisfacer esos pedidos, le dijo resignadamente:

Está usted muy recomendado, Alegría, muy recomendadito (Varona, 2008: 99).

A fines de 1934, luego del frustrado movimiento revolucionario de El Agustino, Alegría fue nuevamente detenido, pero esta vez el prefecto de Lima, Jorge Meave, «amigo de mi papá y de toda la familia», luego de un interrogatorio bastante amable, le preguntó qué podía hacer por él. Como no podía liberarlo, Alegría le dijo que prefería el destierro a la cárcel.

No iba a convertirme en un héroe de la ergástula, siendo que además Meave actuaba como un amigo (Varona, 2008: 118).

Alegría fue enviado al exilio. El diario del padre de Villanueva del Campo consigna, por ejemplo, que el lunes 18 de mayo de 1936, «Armando fue puesto en libertad por gestiones del comandante Aurelio de la Guerra, amigo nuestro» (Villanueva del Campo \& Thorndike, 2004: 85). Es posible que Villanueva no hubiera aprobado dichas gestiones -el padre mismo consigna en su diario que Armando «no desea gozar de preferencias»—-(Villanueva del Campo \& Thorndike, 2004: 62), pero lo cierto es que las gestiones se hacían y daban resultado. Esto se repitió en enero de 1940:

Salí en libertad gracias a mi padre y no a una negociación del partido. El visitó a todos sus amigos influyentes hasta que al fin el Ministro Garrido Lecca, que manejaba la cartera de Gobierno, facilitó las cosas (Villanueva del Campo \& Thorndike, 2004: 177, énfasis agregado). 
Detenido nuevamente en 1942, Villanueva fue llevado delante del propio ministro Mier y Terán, quien le dijo que «aunque [los presos políticos] estuvieran dentro de los márgenes del delito, se los trataba con toda consideración» (Villanueva del Campo \& Thorndike, 2004: 247). Mier y Terán lo trató «cordialmente» e incluso le asignó «alimentación de primera» (Villanueva del Campo \& Thorndike, 2004: 253). Luis Felipe de las Casas fue liberado y enviado al exilio a comienzos de 1935 «por gestiones de mi familia ante las autoridades» (De las Casas, 1981: 46). Este tipo de gestiones y concesiones estaban al alcance de ciertos militantes y dirigentes cuya condición social les aseguraba contactos importantes dentro de la estructura administrativa del gobierno, pero no siempre incluían a los militantes de base y mucho menos a los presos comunes, un hecho que reforzaba la diferenciación al interior de la comunidad carcelaria.

En el caso de militantes de condición social más modesta las gestiones se hacían a través de cartas en las que la retórica combinaba, de manera muy sugerente, un discurso de reivindicación y denuncia con ciertas formas de adulación hacia las autoridades de turno. Las solicitudes eran, por lo general, bastante razonables, y no implicaban necesariamente la búsqueda de condiciones privilegiadas. Pero sí revelan que los presos políticos o sus familiares habían entendido claramente que, a veces, los reclamos airados, las huelgas de hambre o las acciones colectivas no eran el mejor camino para conseguir ciertos objetivos. En mayo de 1935, por ejemplo, el preso político César Salmón solicitó su traslado de El Frontón a la penitenciaría:

Un sitio ideal para mis actividades (...) allí existen variados talleres, en uno de los cuales deseo perfeccionarme para cuando salga a la vida libre me sirva para hacer frente a la lucha por la existencia [y] ser útil, más tarde, a la sociedad y a la patria27.

Un preso aprista escribió al Inspector General de Prisiones para interceder por su compañero García Mendizábal, quien había sido sometido a castigos severos y enviado al Frontón:

Yo invoco Sr. Inspector sus sentimientos humanos en favor de Garcia Mendizabal y refuerzo mi solicitud con los excelentes antecedentes de conducta del mismo 28 .

¿Conocían los dirigentes apristas de este tipo de gestiones? ¿Eran consultadas y aprobadas por la organización al interior de la cárcel? En otros casos eran familiares los que hacían las gestiones. Ese fue el de Héctor Pretel, un reconocido militante aprista condenado por la Corte Marcial de Trujillo por su participación en la insurrección de 1932 y que había logrado fugarse de la penitenciaría el 1 de septiembre de 1935. Fue recapturado y recluido en El Frontón. En febrero de 1937 su hermana, Zoila Pretel, se dirigió al Ministro de Justicia para pedirle que cese «la tortura inhumana» a la que estaba sometido, «convencida (...) que 
Ud. Señor Ministro no tiene conocimiento de tales torturas». Apela a su «espíritu patriótico [y] humano» para detener esos maltratos «que desdicen y desprestigian al buen gobierno del que tan dignamente forma Ud. parte». Finalmente, apela a su condición de mujer cuya «débil voz», espera, será escuchada29. En otra oportunidad las madres de los sentenciados por la rebelión de Trujillo se dirigieron al propio presidente Benavides solicitando el indulto para ellos:

El pueblo peruano no pasará esta pascua con regocijo si no ve retornar a sus hogares a las decenas de ciudadanos que, con su prisión, exhiben todavía ante el país los rezagos de aquellas sentencias que costaron tanta sangre a la Nación peruana i cuyos recuerdos deben quedar totalmente borrados ahora que ya han pasado ocho meses que inició Ud. con tanto acierto, la política de Concordia i Pacificación 30.

Estos casos permiten subrayar varios elementos de este tipo de gestiones: en ellas se combina, por un lado, un cierto discurso reivindicativo de la condición de presos políticos de los detenidos, un énfasis en la sensibilidad especial que supuestamente encarnaban las mujeres, la denuncia de las condiciones en que se encontraban los presos apristas y la apelación al supuesto espíritu bondadoso y el sentido de responsabilidad del funcionario respectivo a quien, además, en el primer caso, se le supone desconocedor de los hechos denunciados y, en el segundo, una voluntad política de buscar la concordia nacional. No es posible negar que detrás de estas gestiones se percibe el grado de angustia que los familiares de los presos políticos padecían al conocer las condiciones a veces inhumanas en que se les confinaba. Este tipo de gestiones nacía de la desesperación por encontrar alguna salida a dicha condición y apelaba como es natural a cualquier argumento que pudiera facilitar esa salida. En esto, los presos apristas y sus familiares no se distinguían de quienes, en otras condiciones y bajo otro tipo de formas de opresión, han recurrido a este tipo de peticiones con la esperanza de mejorar sus condiciones de existencia.

\section{CONCLUSIÓN}

En la construcción oficial de la memoria aprista, la experiencia de la prisión política ha sido generalmente narrada como una historia de sacrificio y heroísmo que, sin ser totalmente falsa o inventada, ha estado al servicio de una versión acrítica de la historia del partido que, a su vez, resultaba funcional a los intereses políticos del mismo. El partido aprista y sus militantes sufrieron formas violentas e injustas de represión — que incluían la prisión pero también el asesinato, la persecución, el exilio y otras formas de hostigamiento y negación de derechos- con estoicismo, fe y mística revolucionaria, sin doblegarse, apegados a la disciplina partidaria y convencidos de la justicia de su causa y de la inevitabilidad de la victoria. Esta 
narrativa deja de lado aspectos importantes de dicha experiencia, sin embargo, que nos pueden ayudar no sólo a corregir la historia y echar luces sobre esas experiencias, sino además -y aquí radican las implicaciones más importantes de este esfuerzo - a entender mejor las conexiones entre la prisión política y el tipo de partido que se fue forjando en esas épocas de enfrentamiento con regímenes autoritarios. En otras palabras, al introducir matices y correctivos en la visión heroica de la prisión política se puede también empezar a analizar la prisión como un espacio de formación partidaria que de una manera u otra contribuyó a reforzar ciertas formas de hacer política y determinadas formas de organizar el partido. Hay unos hilos conductores que conectan, primero, lo que pasaba en la cárcel con lo que pasaba fuera de ella, y segundo, la experiencia de la represión con la trayectoria del APRA en las épocas de libertad. Aquí conviene subrayar dos aspectos a manera de conclusión. Primero, el carácter cerrado, disciplinado y jerárquico del partido se veía reflejado - y su vez se reforzaba - al interior de la cárcel a través de las formas organizativas y el funcionamiento de jerarquías entre los presos políticos, así como en las comunicaciones entre los dirigentes de afuera y los militantes de adentro. El énfasis en la disciplina y la moral partidaria que se aprecia en las cartas de Haya de la Torre pero también en numerosos escritos de militantes apristas contribuyó decisivamente a consolidar la naturaleza vertical del partido, según la cual la disciplina era entendida como la adhesión a ciertos principios y normas que, por lo general, emanaban desde arriba y se imponían de manera antidemocrática. Segundo, el uso combinado de formas abiertas de resistencia y mecanismos individuales de negociación de derechos, favores o privilegios, puede ayudar a iluminar las maneras en que se fue consolidando, a nivel de la militancia y en las relaciones entre ella y la dirigencia, una cierta cultura política que el APRA desarrollaría a lo largo de su historia. La respuesta de los presos políticos combinaba un discurso y unas formas de resistencia y lucha por un lado con unas prácticas de negociación por otro. La historia de la prisión política debe ser vista en toda su complejidad y, al mismo tiempo, ser recuperada como un elemento central en el desarrollo organizativo y la evolución política del Partido Aprista.

\section{Agradecimientos}

Agradezco a Ricardo Melgar Bao y Steven Hirsch por la invitación a participar de la mesa redonda sobre el APRA en el marco del Congreso Internacional de Americanistas en México en 2009 y a ellos y los demás participantes por sus comentarios. Las observaciones y sugerencias de Marco León y Lissell Quiroz-Pérez fueron muy útiles para mejorar el texto. Mi gratitud principal es para Chloé Constant, Camille Boutron y Anne-Marie Brougère, quienes hicieron posible su publicación en este número especial del Boletín del IFEA. 


\section{Referencias citadas}

\section{Fuentes primarias}

Archivo General de la Nación, Serie 3.20, Ministerio de Justicia Archivo General de la Nación, Serie 3.9, Prefectura de Lima Archivo Luis Heysen

\section{Fuentes secundarias}

AGUIRRE, C., 2001 - Disputed Views of Incarceration in Lima, 1890-1930: The Prisoners' Agenda for Prison Reform. In: Crime and Punishment in Latin America. Law and Society Since Late Colonial Times (R. Salvatore, C. Aguirre \& G. Joseph, eds.): 342368; Durham: Duke University Press.

AGUIRRE, C., 2005 - The Criminals of Lima and their Worlds: The Prison Experience (18501935), 310 pp.; Durham: Duke University Press.

AGUIRRE, C., 2013 - La cárcel y la ciudad letrada: hacia una historia cultural de la prisión en el Perú del Siglo Veinte. Ponencia presentada en el Simposio «Delitos, policías y justicia en América Latina», Universidad Alberto Hurtado, Santiago de Chile, 8-10 de abril de 2013.

BAZÁN VERA, B., 2005 - Vida en El Frontón y otros relatos. Manuscrito.

BUNTMAN, F., 2003 - Robben Island and Prisoner Resistance to Apartheid, 340 pp.; Cambridge: Cambridge University Press.

CALVEIRO, P., 1998 - Poder y desaparición: los campos de concentración en Argentina, 174 pp.; Buenos Aires: Colihue.

COX, C. M. (ed.), 1946 - Cartas de Haya de la Torre a los prisioneros apristas, 99 pp.; Lima: Editorial Nuevo Día.

DE LAS CASAS, L. F., 1981 - El sectario, 291 pp.; Lima: Centro de Investigación y Capacitación, Editora Ital Perú.

GIESECKE, M., 2010 - La insurrección de Trujillo. Jueves 7 de julio de 1932, 371 pp.; Lima: Fondo Editorial del Congreso del Perú.

HEYSEN, L., 1933 - Prólogo. In: Por el APRA (En la cárcel, al servicio del P.A.P.): 13-31; Lima: Editorial Cooperativa Aprista Atahualpa.

MANRIQUE, N., 2009 - «iUsted fue aprista!». Bases para una historia crítica del APRA, 439 pp.; Lima: Fondo Editorial de la Pontificia Universidad Católica del Perú.

MENESES, R., 1933 - Por el APRA (En la cárcel, al servicio del P.A.P.), 118 pp.; Lima: Editorial Cooperativa Aprista Atahualpa.

MOLINERO, C., TINTÓ SALA, M. \& SOBREQUÉS I CALLICÓ, J., 2003 - Una inmensa prisión: los campos de concentración y las prisiones durante la guerra civil y el franquismo, 358 pp.; Barcelona: Crítica.

MURILLO, P., 1976 - Historia del APRA, 1919-1945, 498 pp.; Lima: Enrique Delgado Valenzuela, editor.

PARTIDO APRISTA PERUANO, 1933 - El proceso Haya de la Torre. Documentos para la historia del ajusticiamiento de un pueblo, 189 pp.; Guayaquil: Imprenta La Reforma.

PORTAL, M., 1945 - Costa sur, 130 pp.; Santiago de Chile: Imprenta Nueva.

PORTAL, M., 1957 - La trampa, 138 pp.; Lima: Ediciones Raíz. 
REEDY, D., 2000 - Magda Portal, la pasionaria peruana: biografía intelectual, 386 pp.; Lima: Ediciones Flora Tristán.

RUJEL DÍAZ, J., 1946 - Estampas de la prisión. Renovación. Tribuna del pensamiento aprista, 23: 6, 16.

SÁNCHEZ, L. A., 1981 - Apuntes para una biografía del APRA. III. La violencia, 1935-1948, 243 pp.; Lima: Mosca Azul Editores.

SEOANE, J., 1937 - Hombres y rejas, 352 pp.; Santiago de Chile: Ediciones Ercilla.

SINGH, U., 1998 - Political Prisoners in India, 293 pp.; Delhi: Oxford University Press.

STEIN, S., 1980 - Populism in Peru. The Emergence of the Masses and the Politics of Social Control, 296 pp.; Madison: University of Wisconsin Press.

TEMOCHE, R., 1955 - Luis Negreiros, mártir, 101 pp.; México: Ediciones Humanismo.

THORNDIKE, G., 1973 - El año de la barbarie: 1932, 298 pp.; Lima: Mosca Azul Editores.

VARONA, D., 2008 - Ciro Alegría y su sombra. Biografía ilustrada, 335 pp.; Lima: Planeta.

VILLANUEVA DEL CAMPO, A. \& G. THORNDIKE, 2004 - La gran persecución (19321956), 512 pp.; Lima: Empresa Periodística Nacional. 